\section{Streptozotocin Treatment of Malignant Islet Cell Tumour}

\section{British Medical fournal, 1970, 3, 562-563}

Hypoglycaemia due to pancreatic islet cell tumours is usually amenable to surgery, but in about $20 \%$ of cases the tumour has metastasized or cannot be found at laparotomy (Marks and Rose, 1965). The prognosis for such cases was greatly improved by the introduction of diazoxide Drash and Wolff, 1964). The antibiotic streptozotocin has been shown to be a powerful pancreatic betacytotoxin (Rakieten et al., 1963; Arison et al., 1967; Junod et al., 1967), and its use in two cases of metastatic insulinoma has been reported (Murray-Lyon et al., 1968; Arnould et al., 1969). We describe a further case successfully treated with streptozotocin.

\section{CASE RePORT}

A 50-year-old man presented in 1964 with episodes of behavioural disturbance and altered consciousness due to hypoglycaemia. Laparotomy revealed a large tumour of the tail of the pancreas and two visible hepatic metastases. Distal pancreatectomy was performed and histology showed a malignant islet cell tumour. Postoperatively intractable hypoglycaemia persisted. Administration of diazoxide $(400 \mathrm{mg}$. daily) led to a dramatic improvement, but over the next four years it was necessary to increase the dose to $600 \mathrm{mg}$. daily and add hydrochlorothiazide $(100 \mathrm{mg}$. daily) to prevent recurrent hypoglycaemia. In June 1968 his hypoglycaemic attacks returned and became more frequent, despite diazoxide 600 mg. daily. On 28 September 1968 he was readmitted to the Royal Free Hospital for observation and investigation. While under observation three hypoglycaemic attacks occurred despite continued therapy with diazoxide and hydrochlorothiazide. It was therefore decided to try streptozotocin. The experimental nature of this treatment was explained to the patient and accepted by him. The response of his blood sugar and plasma insulin to this drug is shown in the Chart.

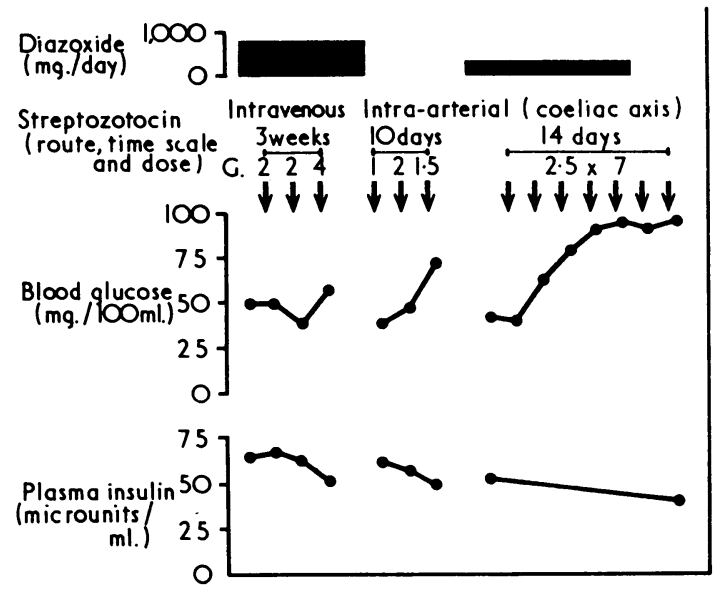

Effect of streptozotocin therapy on mean preprandial blood sugar and plasma insulin levels.

Over a three-week period three intravenous infusions of streptozotocin $(2 \mathrm{~g} ., 2 \mathrm{~g}$., and $4 \mathrm{~g}$.) were given. Immediately before use it was dissolved in $500 \mathrm{ml}$. of normal saline. The first two infusions were given over a period of two hours and the third over one hour. Nausea and vomiting were experienced on each occasion for a few hours. After the first infusion hypoglycaemic attacks ceased, but no appreciable rise in blood sugar occurred until after the 4-g. infusion. There was a small fall in plasma insulin following this course of treatment. Nevertheless, preprandial blood sugar levels of less than $50 \mathrm{mg}$. $/ 100 \mathrm{ml}$. were obtained on several occasions, which made further treatment necessary.

At this stage only $4.5 \mathrm{~g}$. of streptozotocin was available; because of this the remainder was given in divided doses directly into the coeliac axis. Three intra-arterial infusions of streptozotocin $(1 \mathrm{~g}$., $2 \mathrm{~g}$., and $1.5 \mathrm{~g}$.) in $40 \mathrm{ml}$. of normal saline were given at five-day intervals with an infusion time of 10 minutes. Nausea and vomiting followed as with the previous intravenous therapy. On the day before the first intra-arterial infusion diazoxide and hydrochlorothiazide therapy was discontinued; this resulted in an initial fall of blood glucose and a rise in plasma insulin. Thereafter each infusion was followed by a slight rise in blood glucose and a fall in plasma insulin. There was a continued absence of symptomatic hypoglycaemia.

No more streptozotocin was available at that time and the patient was discharged free from symptoms on 21 December. Within three weeks he was experiencing recurrent hypoglycaemic attacks, but these were controlled temporarily by reintroduction of diazoxide therapy at less than half the previous dosage. He was readmitted on 9 March 1969 for a further course of treatment with streptozotocin.

Over 14 days we gave seven infusions of streptozotocin $(2.5 \mathrm{~g}$ dissolved in $30-100 \mathrm{ml}$. of saline) via the coeliac axis with an infusion time of 10-15 minutes. Blood sugar rose progressively. Diazoxide was stopped after the fifth infusion, when moderate glycosuria and postprandial blood sugar levels of up to 180 mg. $/ 100 \mathrm{ml}$. were found. After this course of therapy his preprandial blood sugar averaged $90 \mathrm{mg} . / 100 \mathrm{ml}$.

Biochemical evidence of hepatic and renal injury appeared at the conclusion of streptozotocin therapy but was not apparent clinically. The serum aspartate transaminase and isocitrate dehydrogenase rose. Arterial $p \mathrm{H}$ fell from 7.47 to 7.37 and the standard bicarbonate from 28 to $18 \mathrm{mEq} / \mathrm{l}$; the ability of the kidney to acidify urine was depressed. There was a fall in serum potassium, calcium, and inorganic phosphorus. Moderate proteinuria and amino-aciduria were detected. Normal hepatic and renal function returned during the next month and the serum electrolyte abnormalities were corrected.

Coeliac axis arteriography before this second course of intraarterial therany showed diminished vascularity of the hepatic metastases compared with three months previously. The diameter of the hepatic artery $(0.95 \mathrm{~cm}$.) showed a slight increase. After the completion of therapy the reduction in vascularity of the hepatic metastases was even more pronounced, but they remained visible and were unaltered in size. The calibre of the hepatic artery was reduced and its diameter $(0.8 \mathrm{~cm}$.) was within normal limits (Blendis et al., 1969).

The patient was followed up for six months. Absence of hypoglycaemic symptoms continued, despite withdrawal of diazoxide therapy. He felt well and had resumed full employment. Blood sugar levels in the near-fasting state continued to average 90 mg./100 ml. (range $65-120 \mathrm{mg}$.) and plasma insulin had fallen to a mean level of 34 microunits $/ \mathrm{ml}$.

\section{COMMENT}

In the present case $2 \mathrm{~g}$. (30 mg. $/ \mathrm{kg}$.) of streptozotocin intravenously did not alter glycaemia, and the response to $4 \mathrm{~g}$. (60 mg. $/ \mathrm{kg}$.) was not impressive. Inadequate peak blood levels due to slow administration may have been responsible. Faster infusion into the coeliac axis seemed more effective. The transient hepatic and renal injuries suggest that the margin between therapeutic and toxic doses may be narrow.

Plasma insulin levels fell after streptozotocin therapy but 
remained above the range to be expected with his blood sugar values. A possible explanation is that some islet cell tumours produce abnormal insulins which are biologically inactive but not immunologically distinct (Samols, 1965).

The principal aim of streptozotocin therapy for malignant insulinoma is the restoration of normoglycaemia. This has been achieved in all reported cases. More radical therapy with streptozotocin may be limited by toxicity, but infusion into the coeliac axis may reduce the risk to tissues other than the liver. Complete destruction of neoplastic tissue seems unlikely in this patient, as high plasma insulin levels have persisted.

ADDENDUM.-Since submission of this paper renal injury has been reported in two cases of metastatic insulinoma treated with intra-arterial streptozotocin (Sadoff, 1969). The drug was given into the aorta, as attempts to catheterize the coeliac axis were unsuccessful and high levels must have been produced in the blood perfusing the kidneys. Since renal toxicity now seems to be the main hazard of streptozotocin therapy, we consider that selective coeliac axis infusion may be especially valuable.

We thank Dr. Charles Rosenbaum, of the National Cancer Institute, U.S.A., and Dr. Keith Taylor, of King's College Hospital, London, for supplying us with streptozotocin. We are grateful to the Departments of chemical pathology and physics at the
Royal Free Hospital for their help with the numerous blood sugar and plasma insulin estimations.

N. N. STANLEY, M.B., M.R.C.P.

Medical Registrar, Department of Medicine, Royal Free Hospital, London N.W.3.

V. MARKS, D.M., M.R.C.P., M.R.C. PATH.

Group Pathologist, West Park Hospital, Epsom.

L. KREEL, M.D., M.R.C.P.

Consultant Radiologist, Royal Free Hospital, London W.C.1.

N. MCINTYRE, M.D., B.SC., M.R.C.P.

Senior Lecturer, Department of Medicine, Royal Free Hospital, London, N.W.3.

\section{REFERENCES}

Arison, R. N., et al. (1967). Diabetes, 16, 51.

Arnould, Y., Ooms, H. A., and Bastenie, P. A. (1969). Lancet, 1, 1210

Blendis, L., Kreel, L., and Williams, R. (1969). Gut, 10, 85.

Drash, A., and Wolff, F. (1964). Metabolism, 13, 487.

Junod, A., et al. (1967). Proceedings of the Society for Experimental Biology and Medicine, 126, 201

Marks, V., and Rose, F. C. (1965). Hypoglycaemia. Oxford, Blackwell.

Murray-Lyon, I. M., et al. (1968). Lancet, 2, 895.

Rakieten, N., Rakieten, M. I., and Nadkarni, M. V. (1963). Cancer Chemotherapy Reports, 29." 91.

Sadoff, L. (1969). Diabetes, 18, 675.

Samols E. (1965). In On the Nature and Treatment of Diabetes, ed B. S. Leibel, and G. A. Wrenshall, p. 227. Amsterdam, Excerpto Medica.

\section{Thromboembolic Pulmonary Hypertension of Unusual Cause in a Teenager}

British Medical fournal, 1970, 3, 563-564

We report the case of a young girl who had fatal thromboembolic pulmonary hypertension, the site of thrombus formation being multiple abnormalities of the pelvic and leg veins.

\section{CASE History}

A girl aged 15 presented with swelling and aching of the right leg. Examination showed generalized leg enlargement with no signs of venous occlusion. She was believed to have an arteriovenous fistula and treatment was not undertaken. Two years later she had developed increasing breathlessness on exertion. An $x$-ray pioture of the chest showed bilateral apical shadowing and some enlargement of the hilar glands. Tests for active tuberculosis were negative, but despite this antituberculous treatment was started. She developed pain and swelling of the left leg and had pitting oedema, a tender calf, tenderness over the long saphenous vein, and a positive Homans' sign. She also had tachycardia, gallop rhythm, and an ejection systolic murmur best heard in the pulmonary area.

Chest $x$-ray picture showed enlargement of the pulmonary arterial trunk and main branches. The electrocardiogram (E.C.G.) showed inversion of the T wave in leads V1 to V4, with right bundle-branch block. Exploration of the femoral vein was carried out. A thrombus extending at least $15 \mathrm{~cm}$. proximal to the inguinal ligament was removed, and failure to pass a Fogarty catheter into the inferior vena cava suggested stenosis at the proximal end of the common iliac vein. After the operation she remained unwell, dyspnoeic, and cyanosed. 'The venous thrombosis was initially slow to settle but responded eventually to anticoagulants. She was then discharged.

One month later she was in heart failure with a large "a" wave in the jugular venous pulse. She was readmitted and right-sided cardiac catheterization showed no evidence of a shunt, but considerable pulmonary hypertension accompanied a greatly increased pulmonary vascular resistance (see Table). An attempt was made to pass a catheter from the right saphenous vein to the inferior vena cava, but it could not be passed beyond the pelvis because of an apparent obstruction. A second catheter was passed from above to the inferior vena cava and angiography was performed (Fig. $1 \mathrm{~A}$, and B). Grossly abnormal pelvic veins were shown. The left iliac vein could not be visualized and the right vein showed filling defects with large anastomotic vessels. A pulmonary arteriogram was also obtained by injecting dye into the right ventricle. This showed severe narrowing of the pulmonary arteries at the primary division, with good filling of the small arteries. A diagnosis of thromboembolic pulmonary hypertension was made and she was discharged home on anticoagulants.

Within a week she was again admitted with pain in the left side of the chest and deep calf-vein thrombosis on the right side, despite apparently well controlled anticoagulant therapy. Chest $x$-ray examination showed areas of opacity in both mid-zones and an E.C.G. showed further right ventricular strain and $P$ pulmonales. In an effort to prevent further emboli inferior vena caval plication was performed. At operation the iliac veins were represented by fibrous bands and there were no normal 